\title{
Domiciliary vs Centre-Based Rehabilitation of Older Community Dwellers: Randomised Trial with Economic Evaluation
}

\author{
Tracy A. Comans ${ }^{1,2}$, Sandy Brauer ${ }^{1}$ and Terry Haines ${ }^{*}, 3,4$ \\ ${ }^{I}$ School of Health and Rehabilitation Sciences, The University of Queensland, Brisbane, Australia \\ ${ }^{2}$ Metro South Community Health, Brisbane, Queensland, Australia \\ ${ }^{3}$ Physiotherapy Department, School of Primary Health Care, Monash University, Frankston, Australia \\ ${ }^{4}$ Continuing Care Section, Southern Health, Cheltenham, Australia
}

\begin{abstract}
Background: Community rehabilitation services for older adults aim to address factors that lead to physical decline and falls and return people to their normal activities in the community. While community rehabilitation has been proven effective in reducing falls in the elderly, previous studies have not specified whether delivering services at home or in a centre-based format is the more appropriate method of service delivery.

Aim: This study aims to compare a centre-based group program with a home-based program. The purpose of this study is to identify the most clinically effective way of delivering community rehabilitation services to older fallers and determine which service delivery setting is more economically efficient.

Methods/Design: This paper describes the study design and methods of a randomised clinical trial. One group of participants will receive a centre-based community rehabilitation service, the other group a domiciliary (home-based) community rehabilitation service of near identical content. Participants in this study are those clients over 60 years of age referred to a community rehabilitation service. Patients referred to this service typically have had recent falls, poor or declining mobility, functional dependency, cognitive decline, and / or physical deconditioning.

Clinical effectiveness will be primarily determined by comparison of health-related quality of life and rates of accidental falls. Secondary outcomes include the levels of participation in functional activities, and physical capacity between the two groups. Economic efficiency will be determined through conduct of a cost-benefit analysis.

Discussion: Results from this study will guide clinicians and policy makers to identify the more effective and efficient falls prevention community rehabilitation program service delivery model for older adults living in the community.
\end{abstract}

Trial Registration: Australian New Zealand Clinical Trials Register: ACTRN12605000056695.

\section{INTRODUCTION}

Declining physical function and falls associated with ageing are a significant public health concern. Many industrialised countries presently face ageing demographics indicating that the relative magnitude of this public health problem will grow in future years [1]. Fall related injury constitutes a significant burden both in the impact of injury on the individual and the cost to society overall [2]. Multidisciplinary rehabilitation services for frail older adults require a holistic collaborative approach to address the factors that lead to physical decline and return people to their normal activities in the community [3]. However there is considerable variation with the structure and type of programs offered by community rehabilitation services worldwide [4]. This study describes the comparison of two programs developed to address functional decline and falls amongst older community dwelling adults; a centre-based group program and a home-based program.

*Address correspondence to this author at the Allied Health Clinical Research Unit, Kingston Centre, Cnr Warrigal and Kingston Rds, Cheltenham, VIC 3192, Australia; Tel: +61 3 92651774;

E-mail: terrence.haines@med.monash.edu.au
Direct comparisons of centre-based and domiciliary models of community rehabilitation have previously focused upon specific patient sub-groups and a variety of different models of centre-based and domiciliary community rehabilitation. For patients following total knee arthroplasty surgery, patients receiving domiciliary therapy in the form of a home exercise program and two telephone calls during the 12 week period following surgery, recorded similar improvements to those receiving centre-based therapy consisting of up to two hour long physiotherapy sessions per week for 12 weeks following surgery [5]. Home-based cardiac rehabilitation services have been shown to have lower costs and be just as effective as hospital group-based programs in randomised controlled trials [6, 7]. Home based rehabilitation has also been demonstrated to be equally effective for patients following stroke as compared to in-patient rehabilitation, and with possibly lower costs $[8,9]$. Similarly, domiciliary rehabilitation has been found to be equally effective and with lower costs in the rehabilitation of patients following a hospital admission due to stroke than centre-based therapy [10]. Despite this growing body of evidence supporting the costminimizing features of domiciliary therapy, there has been a paucity of investigation amongst more generalised, frail, 
older, community-dwelling people who are not specifically receiving rehabilitation due to recent surgery or a cardiovascular event.

The aim of this project is to compare centre-based and home-based models of delivering services focused on preventing functional decline and falls amongst communitydwelling older adults and to compare their economic efficiency.

\section{METHODS}

\section{Design}

This study is a randomised trial with blinded outcome assessment at baseline, 8 week and 6month follow up points. One group of participants will receive a centre-based community rehabilitation service, the other group a domiciliary (home-based) community rehabilitation service. Models will be compared for economic efficiency via a cost-benefit analysis.

\section{Subjects and Setting}

The community rehabilitation services provided in this trial will operate from the Metro South Community Rehabilitation Team, Brisbane, Australia. Participants in this study will be recruited from older adults referred to the service from three hospital emergency departments located in the region following a presentation for a fall and from local general practitioners. Patients referred to this service typically have had recent falls, poor or declining mobility, experience functional dependency, cognitive decline, and / or physical deconditioning.

Subjects will be eligible for inclusion to the trial if they are aged >60years and able to complete a Timed up and Go Test [11]. Subjects will be excluded from the study if they are a nursing home resident, are non-ambulant or are assessed by an Occupational Therapist or Physical Therapist as being unable to participate in a community rehabilitation program due to cognitive and/or physical function.

This trial has been registered on the Australian New Zealand Clinical Trials Register: ACTRN12605000056695. The trial has received ethical clearance from the The University of Queensland Medical Research Ethics Committee; Clearance Number: 2005000318 and from the Princess Alexandra Hospital Human Research Ethics Committee.

\section{Interventions}

The program was developed by using a multifactorial approach to falls intervention including Tai Chi, circuit train- ing, specific balance training, strength training and education modules. These interventions have been demonstrated to reduce the risk of falls amongst older adults in recent systematic reviews and meta-analyses of randomised controlled trials [12-14].

The program consists of either a centre-based service conducted at a local hospital rehabilitation gym or a home based service which includes specific balance training, functional strength training, education and upper limb training interventions for 1 to 1.5 hours once per week for 8 weeks. The 3 modules for each setting are detailed bin Table 1 .

Patients from both groups also receive a tailored home exercise program of three exercises from a physiotherapist.

\section{Outcome Measures}

At the initial assessment basic demographic information (Table 2) is collected such as age, sex, type of housing and whether a carer is available. The outcome measures (Table 3) are collected at the initial, 8 week and 6 month assessment times. The measures have been categorised according to the International Classification of Functioning, Disability and Health framework [15-17] into a 'best fit' with the recognition that many measures (for example Frenchay Activities Index) do not fit neatly into one category but span two or three classifications.

The primary outcome measures are rates of accidental falls as a measure of the overall performance of the falls prevention program and health related quality of life as this is considered to be the key goal for health promotion in older people [18]. The EQ5D was chosen as the primary measure as it is a simple, easy to administer reliable and valid tool measuring five dimensions of health $[19,20]$.

\section{Procedure}

Subjects will be recruited to the study using the pathway defined in Fig. (1).

All patients receive an initial joint home visit from an occupational therapist and physiotherapist. Baseline data will be collected at the initial home visit by staff trained in collection of baseline measures. All measures are collected at the initial assessment prior to group allocation so that the therapists collecting the initial data are blinded to group allocation until after the assessment is completed. Patients will be asked for informed consent to participate in the project if they meet other project inclusion / exclusion criteria. Informed consent will be obtained from the person directly or from the next of kin if the subject had a previously demon-

Table 1. Program Modules

\begin{tabular}{|c|c|c|}
\hline Module & Group & Domiciliary \\
\hline Balance and strength & $\begin{array}{l}\text { Warm-up of modified Tai Chi [28], balance workstations, } \\
\text { indoors walking circuit and lower limb strengthening exer- } \\
\text { cises (30 mins) }\end{array}$ & $\begin{array}{l}\text { Warm-up of modified Tai Chi, balance worksta- } \\
\text { tions, outdoors walking and lower limb strengthen- } \\
\text { ing exercises ( } 30 \text { mins) }\end{array}$ \\
\hline $\begin{array}{l}\text { Education (same for both groups) } \\
\qquad 30 \mathrm{mins}\end{array}$ & \multicolumn{2}{|c|}{$\begin{array}{l}\text { Verbal education and discussion group. Based on a framework of chronic disease self management [29]. The topic of } \\
\text { education changes each week, and covers topics of falls prevention, promoting physical activity, self efficacy for } \\
\text { chronic disease management, goal setting and review, medication management, continence, relaxation, stress man- } \\
\text { agement, and accessing community services (30 minutes). }\end{array}$} \\
\hline Functional tasks & $\begin{array}{l}\text { Upper limb strengthening and functional activities in stand- } \\
\text { ing (30 mins) }\end{array}$ & $\begin{array}{l}\text { Functional upper limb tasks such as cooking with } \\
\text { occupational therapist (15-30mins) }\end{array}$ \\
\hline
\end{tabular}


Table 2. Demographic Features of the Population

\begin{tabular}{|c|c|c|c|}
\hline ICF Construct & Descriptor & Measurement Name & Scaling \\
\hline \hline \multirow{3}{*}{ Body Structure and Function } & \multirow{2}{*}{ Sensory } & Vision - Reading [30] & self-rated 5 point scale \\
\cline { 2 - 4 } & & Vision - Long Distance & self-rated 5 point scale \\
\cline { 2 - 4 } & & Hearing & self-rated 5 point scale \\
\cline { 2 - 4 } & Continence & Continence - Bladder & yes/no \\
\cline { 2 - 4 } & Medications & Medications & Number and number relating to falls risk \\
\cline { 2 - 4 } & ICD codes & Health Conditions & Number and categorised according to ICD-10 codes \\
\hline Activity & Mobility & Walking Aid & Type \\
\hline Activity/Participation & Mobility & Driving & yes/no \\
\hline Environmental Factors & Physical Environment & Environmental Audit & Number of recommendations by an occupational therapist \\
\hline \multirow{2}{*}{ Personal Factors } & \multirow{2}{*}{ Lifestyle } & Smoking & yes/no \\
\cline { 2 - 4 } & & Alcohol-how often & yes/no and quantity \\
\hline
\end{tabular}

Table 3. Outcome Measures

\begin{tabular}{|c|c|c|c|}
\hline Construct & Descriptor & Measurement Name & Scaling \\
\hline \multirow{5}{*}{$\begin{array}{l}\text { Body Structure and } \\
\text { Function }\end{array}$} & Weight Maintenance & BMI & Weight/Height in metres squared \\
\hline & Muscle Power & Quads Strength & KG using hand held dynamometer \\
\hline & Muscle Power & Lateral Pinch Test & KG using hand held dynamometer \\
\hline & Mental Functions & AMTS $[31,32]$ & Score out of 10 \\
\hline & Mental Functions & K10 Scale [33] & Score out of 50 \\
\hline \multirow{6}{*}{ Activity } & Falls & Falls & $\begin{array}{l}\text { Number of in previous six months and number in six month } \\
\text { follow up period }\end{array}$ \\
\hline & Mobility & Timed Up and Go [11] & Time in seconds \\
\hline & Balance & Step Test $[34,35]$ & Number in 15 seconds \\
\hline & Balance & Romberg $[34,35]$ & Seconds \\
\hline & Reaction speed & $\begin{array}{l}\text { Simple Reaction Time } \\
\text { Test }\end{array}$ & Time in milliseconds \\
\hline & Upper limb dexterity & 9 Hole Peg Test [36] & Time in seconds \\
\hline \multirow{2}{*}{ Activity/Participation } & Mobility & Driving & yes/no \\
\hline & Global & Frenchay [37] & Score out of 30 \\
\hline Environmental Factors & Support and Relationships & Caregiver Strain [38] & Score out of 13 \\
\hline \multirow[t]{2}{*}{ Personal Factors } & Attitudes & $\begin{array}{l}\text { Home Exercise Compli- } \\
\text { ance(survey applied } \\
\text { from) [39] }\end{array}$ & Questionnaire with 5 point likert scale \\
\hline & Lifestyle & Nutrition Score [30] & score out of 13 \\
\hline Quality of Life & Global & EQoL $[40,41]$ & EQ5-D score out of 1.0 EQ VAS score from 0-100 \\
\hline \multirow{3}{*}{ Economic Variables } & Value & Costs - Service & $\begin{array}{c}\text { Amount in \$ measuring the total costs of providing either the } \\
\text { home based or centre based service }\end{array}$ \\
\hline & Value & Costs - Consumer & $\begin{array}{l}\text { Amount in } \$ \\
\text { Amount spent on health care in six months prior to commenc- } \\
\text { ing treatment and six months after commencing treatment }\end{array}$ \\
\hline & Value & $\begin{array}{l}\text { Contingent Valuation - } \\
\text { Willingness to Pay }\end{array}$ & $\begin{array}{l}\text { Amount in } \$ \text { client willing to pay for one session from the } \\
\text { community rehabilitation service }\end{array}$ \\
\hline
\end{tabular}

strated cognitive impairment (Mini-Mental State Examination score < 23 / 30). Patients will be randomised and provided with one of the two eight week intervention programs.
Eight week and six month reassessments will be conducted by a research assistant who will be blinded to group allocation. Both clinical and economic (cost and contingent 


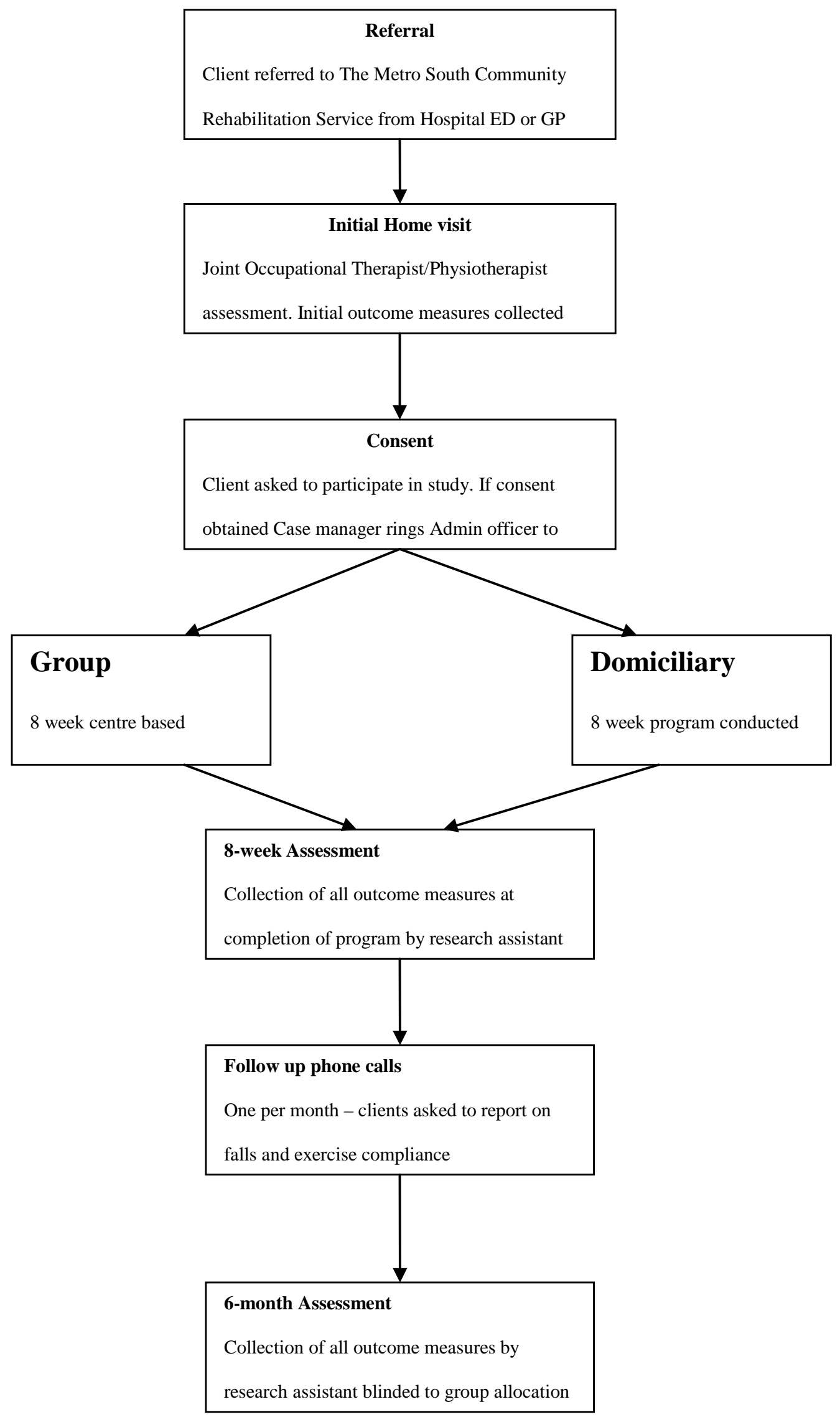

Fig. (1). Flow chart. 
valuation) outcomes will be collected at these times. The principal investigator will also conduct monthly telephone contact between the eight week and six month assessment to collect information about falls in the previous month.

\section{Randomisation}

A list of computer generated random numbers was used to allocate subjects to home or centre-based treatment. This sequence was placed into sealed, opaque, numbered envelopes. These envelopes are kept with administration staff not connected with the research project. Following provision of written patient consent and completion of the initial assessment, the assessing therapist will contact the administration staff who open the next envelope in the sequence and inform the therapist of the allocation group. This is to ensure the principal researcher and therapists providing the treatment are concealed from the allocation process.

\section{Statistical Analysis}

Outcomes measured on a continuous scale will be compared between groups and across time periods using a generalised estimating equation (GEE) approach. The design of the study is longitudinal with repeated measurements which are correlated with one another in an individual. The GEE is a flexible way of analysing this type of design which takes into account the correlation between measures within an individual and also is able to handle missing data points from individual participants over a time series [21]. The GEE can also compare groups based on outcomes measured as "counts" (for example, falls) by specifying a Poisson or negative binomial family for the dependent variable in the analysis. Adjustment for differences observed between groups in variables measures at the baseline assessment will also be made when comparing groups on outcome measures.

The principal economic analysis will take a societal perspective taking into account the costs and benefits to the health care system and to the individual. The analysis will employ a cost-benefit technique with benefits measured using contingent valuation. This technique offers several benefits over other economic methods [22]. It allows for the use of a single metric for costs and consequences (dollar value), it greatly simplifies the estimation of uncertainty around cost-effectiveness results [23], health outcomes measured can be readily compared with non-health outcomes and outcomes couched in monetary terms may be more comprehensible and familiar for decision-makers. The format of the contingent valuation question is demonstrated in Box $\mathbf{1}$.

Criticisms of the cost-benefit approach include that it favours the wealthy in programme allocation and that there are measurement issues in valuing the output of health care programs in dollar values [24]. As a result this will be a conservative estimate of the benefit of this program due to the majority of participants in this program being elderly and dependent on government benefits. This protocol also describes collection of sufficient outcomes such as falls, health service resource use, and patient health-related quality of life to allow for either cost-minimisation, cost-effectiveness, or cost-utility economic evaluation approaches to be employed. Economic evaluation will include sensitivity analysis to adjust for uncertainty in costing for both centre-based and domiciliary therapy approaches.

\section{Box 1. Willingness to Pay Question}

I want to ask you a question to help us determine how much clients value our service.

This is a theoretical question, please understand that we will not be asking you to pay any money for the service you have received or make others pay in the future. It is a free service.

I want you to think about the entire service you have had from the community rehab team from the first treatment session to the last and any benefits you may have received from it.

We would like to know how much one of these sessions is worth to you. Imagine we asked clients to pay for sessions at the time of the visit out of their own pocket. We would like to know the maximum amount you would you be willing to pay for one of these sessions that you received from the $\boldsymbol{C R S}$. If we offered you the service you have received at a cost of $\$ X$ (randomly selected 10,30 or 50 ) per session would you choose to receive the service? Yes or No.

Keep in mind that you will have this amount less to spend on other things each week. Do you think this represents a realistic estimate of the maximum amount that you would pay?

\section{Power Calculation}

Power calculations were based on an expected Health related Quality of Life benefit on the weighted EQ-5D [25] with minimal relevant effect size of 0.1 based on a $10 \%$ change in health status and a standard deviation of $(0.25)$ based on previously reported calculations from various patient sub-groups [26, 27]. Sample size was calculated at 36 persons per group at $80 \%$ probability based on a repeated measures ancova with $\mathrm{r}=0.7$ between follow up measures. Factoring in an attrition rate of $20 \%$ (mortality, too unwell to continue, unwilling to participate) it is proposed that 90 people in total will be required.

\section{DISCUSSION}

The treatment protocols developed in this study were specifically designed for preventing falls in a frail, older population. These models should be easily transferable to other settings where the primary focus is preventing falls in this patient cohort. This project will also help to define a superior service delivery models for community rehabilitation services of the options compared that aim to reduce falls, improve quality of life and participation levels for older community dwelling adults. It will also provide information to assist in identifying the most cost-effective service delivery model for community rehabilitation services.

This study design is a pragmatic clinical trial which will recruit frail elderly clients with differing morbidities for example with diagnosis of stroke or orthopaedic condition or frailty. This could make comparisons between groups difficult as the different conditions will impact on the client's outcomes in the program. In addition the expected age and frailty of the cohort may mean additional dropouts due to illness and death. However, the authors believe it is important to research this cohort as the aging population in western demographics will become an increasingly important and growing area of rehabilitation and robust clinical trials are needed in this area to determine the best way of managing these elderly clients with co-morbid conditions.

\section{ACKNOWLEDGEMENTS}

The project was commenced in June 2005 with a grant of $\$ 37000$ from Queensland Health. This research is currently 
supported with a grant from the Community Rehabilitation Research Scholarship Scheme (Queensland Health).

Thanks to Michelle Currin, Fiona Bourke and Catherine Peters from the Brisbane South Community Rehabilitation Service for help in developing the models of care.

\section{ABBREVIATION}

\section{GEE = Generalized Estimating Equation}

\section{REFERENCES}

[1] Moller J. Changing health resource demands for injury due to falls in an ageing population. New South Wales Public Health Bulletin 2002; 13(1-2): 3-6.

[2] Moller J. Changing health resource demands for injury due to falls in an ageing population. NSW Public Health Bull 2002; 13: 1-2.

[3] Coppola S, Rosemond CA, Greger-Holt N, et al. Arena assessment: evolution of teamwork for frail older adults. Top Ger Rehab 2002; 17(3): 13-28.

[4] Wade D. Community rehabilitation. Clin Rehab 2001; 15: 575.

[5] Kramer JSM, Bourne R, Rorabeck C, Vaz M. Comparison of clinic- and home-based rehabilitation programs after total knee arthroplasty. Clin Orthop Relat Res 2003; 1(410): 225-34.

[6] Collins LSP, Gargett S. Cost-analysis of gym-based vs home-based cardiac rehabilitation programs. Aus Health Rev 2001; 24: 51-61.

[7] Miller N HW, Berra K, DeBusk F. Home vs group exercise training for increasing functional capacity after myocardial infarction. Circulation 1984; 70: 645-9.

[8] Anderson C, Mhurchu C, Rubenach S, Clark M, Spencer C, Winsor A. Home or hospital for stroke rehabilitation? Results of a randomised controlled trial: II: cost minimization analysis at 6 months. Stroke 2000; 31: 1032-7.

[9] Anderson C, Rubenach S, Mhurchu C, Clark M, Spencer C, Winsor A. Home or hospital for stroke rehabilitation? Results of a randomized controlled trial: I: health outcomes at 6 months. Stroke 2000; 31: 1024-31.

[10] Gladman JFA, Young J. Hospital- and home-based rehabilitation after discharge from hospital for stroke patients: Analysis of two trials. Age Ageing 1995; 24: 49-54.

[11] Podsiadlo D, Richardson S. The timed "up \& go": A test of basic functional mobility for frail elderly persons. J Am Ger Soc 1991; 39: $142-8$.

[12] Gillespie LD, Robertson MC, Lamb SE, Cumming RG, Rowe BH. Interventions for preventing falls in elderly people (Cochrane Review). Cochrane Library, wwwcochraneorg. 2002.

[13] Chang JT, Morton SC, Rubenstein LZ, et al. Interventions for the prevention of falls in older adults: systematic review and metaanalysis of randomised clinical trials. BMJ (Clin Res Ed) 2004; 328(7441): 680 .

[14] Wu G. Evaluation of the effectiveness of Tai Chi for improving balance and preventing falls in the older population--a review. J Am Ger Soc 2002; 50(4): 746-54

[15] Salter K, Jutai JW, Teasell R, Foley NC, Bitensky J. Issues for selection of outcome measures in stroke rehabilitation: ICF body functions. Disab Rehab 2005; 27(4): 191-207.

[16] Salter K, Jutai JW, Teasell R, Foley NC, Bitensky J, Bayley M. Issues for selection of outcome measures in stroke rehabilitation: ICF Participation. Disab Rehab 2005; 27(9): 507-28.

[17] Salter K, Jutai JW, Teasell R, Foley NC, Bitensky J, Bayley M. Issues for selection of outcome measures in stroke rehabilitation: ICF activity. Disab Rehab 2005; 27(6): 315-40.

[18] Borowiak E, Kostka T. Predictors of quality of life in older people living at home and in institutions. Aging-Clin Exp Res 2004; 16(3): 212-20.
[19] Coast J, Peters TJ, Richards SH, Gunnell DJ. Use of the EuroQoL among elderly acute care patients. Quality Life Res 1998; 7(1): 110.

[20] Dorman PJ, Waddell F, Slattery J, Dennis M, Sandercock P. Is the EuroQol a valid measure of health-related quality of life after stroke? Stroke 1997; 28(10): 1876-82.

[21] Burton LGPS. Extending the simple linear regression model to account for correlated responses: An introduction to generalized estimating equations and multi-level mixed modelling. Stat Med 1998; 17(11): 1261-91.

[22] Drummond MF, O'Brien B, Stoddart GL, Torrance GW. Methods for the Economic Evaluation of Health Care Programmes. $2^{\text {nd }} \mathrm{ed}$ Oxford: Oxford University Press; 1997.

[23] Bayoumi AM. The measurement of contingent valuation for health economics. Pharmaco Econ 2004; 22(11): 691-700.

[24] Garber AM, Phelps CE. Economic foundations of costeffectiveness analysis. J Health Econ1997; 16(1): 1-31.

[25] Dolan P. Modelling valuations for EuroQol health states. Med Care 1997; 35(11): 1095-108.

[26] Tidermark J. Responsiveness of the EuroQol (EQ 5-D) and the SF36 in elderly patients with displaced femoral neck fractures. Qual Life Res 2003; 12(8): 1069-79.

[27] Moock J, Kohlmann T. Comparing preference-based quality-of-life measures: results from rehabilitation patients with musculoskeletal, cardiovascular, or psychosomatic disorders. Qual Life Res 2008, 17(3): 485-95.

[28] Lam P. In: Kieffer N, Ed. Tai Chi for Beginners Handbook. $1^{\text {st }}$ ed. Narwee NSW: East Acton 2002

[29] Lorig K, Holman H, Sobel D, Laurent D, Gonzalez V, Minor M. Living a health life with chronic conditions: self management of heart disease, arthritis, diabetes, asthma, bronchitis, emphysema \& others. Boulder, Colorado: Bull Publishing Company; 2000.

[30] Health Q. ONI (Ongoing Needs Identification Tool). 2006 [updated 2006; cited]; Available from: http://www.health.qld.gov.au/hacc/ ONInteractive.asp

[31] Folstein M, Folstein S, McHugh P. Mini-mental state: A practical method for grading cognitive state of patients for the clinician. J Psych Res 1975; 12: 189-98.

[32] Hodkinson H. Evaluation of a mental test score for assessment of mental impairment in the elderly. Age Ageing 1972; 1: 233-8.

[33] Kessler RC, Mroczek. Final Version of our Non-specific Psychological Distress Scale [memo dated 10/3/94]. : School of Survey Research Center of the Institute for Social Research. University of Michigan. Contract No.: Document Number; 1994.

[34] Newton R. Review of tests of standing balance abilities. Brain Injury 1989; 3(4): 335-43.

[35] Whitney SL, Poole JL, Cass SP. A review of balance instruments for older adults. Am J Occup Ther Assoc 1998; 52(8): 666-71.

[36] Grice KO, Vogel K, Le V, Muniz S. Adult norms for a commercially available Nine Hole Peg Test for finger dexterity. Am J Occup Ther 2003; 57(5): 570-3.

[37] Turnbull J, Kersten P, Habib M, McLellan L, Mullee M, George S. Validation of the frenchay activities index in a general population aged 16 years and older. Arch Phys Med Rehab 2000; 81: 1034-8.

[38] Robinson B. Validation of a caregiver strain index. J Gerontol 1983; 38(3): 344-8.

[39] Eccles JS, Wigfield A. Motivational beliefs, values, and goals. Annu Rev Psychol 2002; 53: 109-32.

[40] Brazier J, Jones N, Kind P. Testing the validity of the Euroqol and comparing it with the SF-36 health survey questionnaire. Qual Life Res 1993; 2(3): 169-80.

[41] Polsky D, Willke RJ, Scott K, Schulman KA, Glick HA. A comparison of scoring weights for the EuroQol derived from patients and the general public. Health Econ 2001; 10(1): 27-37. 